Buana Sains Vol 17 No 2: 181-188, 2017

\title{
ANALISIS KOMPARATIF PENDAPATAN USAHATANI TEBU PETANI KKP-E DAN PETANI NON KKP-E (Studi Kasus Desa Bululawang Kecamatan Bululawang Kabupaten Malang)
}

\author{
Ninin Khoirunnisa dan Reza Prakoso Dwi Julianto
}

Fakultas Pertanian Universitas Tribhuwana Tunggadewi Malang

\begin{abstract}
Sugarcane farming income can be increased by the good application of farming technology and the capital. This study aims to analyze sgarcane farming income between the sugarcane use Kredit Ketahanan Pangan dan Energi (KKP-E) and farmers not utilise of KKP-E. This research take loctions in Bululawang Village Bululawang Subdistrict Malang District purposefully. The determination of sample done by using simple random method. The data collection was done with the interview method, observation, and documentation. The data analysis method used farming analysis and the average different test. The research result show that between the average farming income of KKP-E farmers and non KKP-E farmers don't have significant difference. This is due to difference componen authors costs farming between KKP-E farmers and non KKP-E farmers only about they take KKP-E or not. So, that the fundamental difference only on the where abouts interest of KKP-E.
\end{abstract}

Keywords: Income Farming, KKP-E and Interst of KKP-E

\section{Pendahuluan}

Peningkatan taraf hidup masyarakat tani dapat dicapai melalui pembangunan pertanian yang berkesinambungan. Pembangunan pada bidang pertanian yang berkesinambungan ditandai dengan adanya kelangsungan produksi yang memberikan keuntungan pada petani dan adanya kebebasan bagi petani untuk menentukan pilihan terbaik dalam berusaha tani. Pembangunan tersebut diharapkan mampu meningkatkan sebagian besar pelaku ekonomi ikut serta dalam menghasilkan, menikmati dan melestarikanhasil pembangunan (Suara Merdeka, 2013).

Gula merupakan salah satu komoditas yang mempunyai posisi strategisdalam perekonomian Indonesia (Badan Litbang Departemen Pertanian, 2008). Peningkatan konsumsi gula yang terjadi di Indonesia tidak sebanding dengan jumlah produksi gula domestik yang mampu dihasilkan. Menurut Wahyudi (2000), penurunan produktivitas gula tersebut disebabkan oleh aplikasi input usahatani tebu yang dilaksanakan petani semakin lama semakin menjauhi standar yang dianjurkan untuk mendekati kinerja potensial. Kekurangan produksi gula tersebut harus ditutupi dengan langkah impor gula (DGI, 2011). Untuk mengurangi ketergantungan akan gula impor dan meningkatkan kemampuan negara dalam pemenuhan kebutuhan akan gula secara mandiri, sejak tahun 2009 pemerintah mencanangkan program swasembada gula.

Menurut Ellis

(1992), peningkatan penerapan teknologi usahatani dimulai dengan meningkatkan penggunaan sarana produksi akan mempengaruhi hasil produksi dan 
N. Khoirunnisa dan R. P. D. Julianto /Buana Sains Vol 17 No 2 : 181-188

pendapatan usahatani yang lebih baik. Akan tetapi kenyataan dilapangan yang menyebabkan penerapan teknologi usahatani tebu tersebut tidak maksimal ialah keterbatasan modal dalam pelaksanaan usahatani tebu. Untuk meningkatkan akses petani dalam memperoleh sarana produksi, maka peran pemerintah dalam menjembatani kemitraan antara penyedia input dengan petani sangat diperlukan (Susilowati, 2012). Untuk mengatasi masalah tersebut perlu adanya bantuan modal berupa kredit. Kredit yang diberikan selain berfungsi sebagai bantuan modal juga merupakan perangsang untuk menerima bimbingan teknik (Wibowo, 2013).

Menurut Ashari (2009), fungsi modal dalam tataran tingkat usahatani,tidak hanya sebagai salah satu faktor produksi tetapi juga berperan dalam peningkatan kapasitas petani dalam mengadopsi teknologi seperti, benih bermutu, pupuk berimbang dan teknologi pasca panen. Cara yang dapat ditempuh untuk meningkatkan produksi dan pendapatan petani salah satunya dengan meningkatkan akses permodalan petani (Fajrina, 2012). Oleh karena itu dalam mendukung upaya peningkatan produksi usahatani tebu petani, pemerintah menerapkan kebijakan peningkatan produksi gula nasional melaluiProgram Akselerasi Peningkatan Produksi Gula Nasional. Yaitu dengan penyediaan fasilitas kredit bersubsidi melalui Kredit Ketahanan Pangan dan Energi (KKP-E) dalam bentuk kredit subsidi pupuk dan biaya garap usahatani tebu. Melalui dana bank pelaksana dan subsidi pemerintah yang berbentuk KKP-E diharapkan dapat membantu petani, khususnya petani tebu untuk mengatasi permasalahan permodalannya. Namun, dengan berjalannya program tersebut masih banyak petani tebu yang tidak mengambil atau memanfaatkan
KKP-E. Oleh karena itu tujuan dari penelitian ini adalah menganalisis perbandingan usahatani tebu antara petani yang mengambil KKP-E dan petani tebu yang tidak mengambil KKPE.

\section{Metode Penelitian}

Penelitian dilaksanakan pada bulan JuliSeptember 2016. Penentuan daerah penelitian dilakukan secara sengaja di Desa Bululawang Kecamatan Bululawang, Kabupaten Malang. Penentuan responden dilakukan dengan menggunakan metode acak sederhana. Responden penelitian ini merupakan anggota kemitraan PG. Krebet Baru Bululawang Malang. Data dikumpulkan dari responden dengan wawancara terstruktur (kuisioner), observasi, dokumentasi dan pengumpulan data sekunder. Teknik analisis data yaitu kuantitatif dengan menggunakan analisis usahatani dan analisis uji beda rata-rata.

\section{Analisis Usahatani}

\section{a.Analisis Biaya Usahatani}

$$
\mathrm{TC}=\mathrm{TFC}+\mathrm{TVC}
$$

Keterangan :

TC : Total Biaya Usahatani (Rp/Ha)

TFC : Total Biaya Tetap Usahatani (Rp/Ha)

TVC : Total Biaya Variabel Usahatani ( $\mathrm{Rp} / \mathrm{Ha})$

\section{b. Analisis Penerimaan Usahatani}

Dalam penelitian ini penerimaan diperoleh dari dua macam yaitu penerimaan dari unsur gula dan penerimaan dari unsur tetes. Perhitungan penerimaan usahatani tebu dapat dilakukan dengan rumus sebagai berikut : 
TRgula $=$ Q $x$ Rendemen $x$ Pgula

Keterangan :

Trgula

: Total penerimaan dari unsur gula $(\mathrm{Rp} / \mathrm{Ha})$

Q : Jumlah produksi tebu (kuintal/Ha)

Rendemen : Jumlah gula yang terkandung dalam $100 \mathrm{~kg}$ tebu

Pgula : Harga jual gula $(\mathrm{Rp} / \mathrm{kg})$

TRtetes $=\mathrm{Q} \times$ Ptetes

Keterangan :

Trtetes : Total penerimaan dari unsur tetes $(\mathrm{Rp} / \mathrm{Ha})$

Q : Jumlah produksi tebu (kuintal/Ha)

Ptetes : Harga/uang ganti tetes per kuintal tebu (Rp/kuintal)

\section{c. Analisis Pendapatan Usahatani}

Analisis ini digunakan untuk menghitung besarnya pendapatan usahatani tebu. Secara operasional dapat dirumuskan sebagai berikut :

$$
\pi=\mathrm{TR}-\mathrm{TC}
$$

Keterangan :

$$
\begin{array}{ll}
\pi & : \text { Pendapatan }(\mathrm{Rp} / \mathrm{Ha}) \\
\text { TR } & : \text { Total revenue atau total } \\
& \text { penerimaan }(\mathrm{Rp} / \mathrm{Ha}) \\
\text { TC } & : \text { Total biaya }(\mathrm{Rp} / \mathrm{Ha})
\end{array}
$$

\section{Analisis Uji Beda Rata-rata}

Langkah-langkah yang dilakukan dalam pengujian hipotesisuntuk menganalisis perbedaan rata-rata tingkat pendapatan usahatani tebu sebagai berikut : a. Hipotesa Statistik

$$
\begin{aligned}
& \mathrm{H}_{0}: \mu_{1}=\mu_{2} \\
& \mathrm{H}_{\mathrm{a}}: \mu_{1}>\mu_{2}
\end{aligned}
$$

Keterangan :

$\mu_{1}$ : rata-rata pendapatan usahatani tebu pada petani KKP-E.

$\mu_{2}$ : rata-rata pendapatan usahatani tebu pada petani non KKP-E.

\section{b. Mencari Varian atau Ragam $\left(\mathcal{S}^{2}\right)$}

Varian atau ragam ini dicari untuk menguji apakah varian diantara keduanya berbeda atau tidak dengan rumus sebagai berikut:

$$
\begin{aligned}
\mathrm{S}_{1}{ }^{2} & =\frac{\sum\left(X_{1}-\bar{X}\right)^{2}}{\left(n_{1}-1\right)} \\
\mathrm{S}_{2}{ }^{2} & =\frac{\sum\left(X_{2}-\overline{X_{2}}\right)^{2}}{\left(n_{2}-1\right)}
\end{aligned}
$$

Keterangan :

$\mathrm{S}_{1}{ }^{2} \quad:$ ragam dari pendapatan usahatani tebu petani KKP-E.

$\mathrm{S}_{2}{ }^{2} \quad:$ ragam dari pendapatan usahatani tebu petani non KKP-E.

$\overline{X_{1}} \quad:$ rata-rata pendapatan usahatani tebu petani KKP-E.

$\overline{X_{2}} \quad:$ rata-rata pendapatan usahatani tebu petani non KKP-E.

$\mathrm{X}_{1} \quad$ : pendapatan usahatani tebu petani KKP-E.

$\mathrm{X}_{2} \quad$ : pendapatan usahatani tebu petani non KKP-E.

$\mathrm{n}_{1} \quad:$ jumlah sampel dari petani tebu petani KKP-E.

$\mathrm{n}_{2} \quad$ : jumlah sampel dari petani tebu petani non KKP-E.

\section{c. Melakukan Uji F}

Setelah melakukan perhitungan ragam maka sebelum melakukan uji $\mathrm{t}$ terlebih dahulu harus melakukan uji $\mathrm{F}$ untuk 
mengetahui varian atau ragam dari masing-masing sampel dengan rumus sebagai berikut :

$$
\mathrm{F}_{\text {hitung }}=\frac{S_{1}{ }^{2}}{S_{2}{ }^{2}}
$$

Keterangan :

$\mathrm{S}_{1}^{2}$ : ragam dari pendapatan usahatani tebu petani KKP-E.

$\mathrm{S}_{2}^{2}$ : ragam dari pendapatan usahatani tebu petani non KKP-E.

\section{d. Melakukan Uji t}

Hasil uji $\mathrm{F}$ menunjukkan $\mathrm{F}_{\text {hitung }}<\mathrm{F}_{\text {tabel }}$ maka menguji hipotesis uji $\mathrm{t}$ menggunakan rumus :

$$
\begin{gathered}
\mathbf{t}_{\text {hitung }}=\frac{\bar{X}_{1}-\bar{X}_{2}}{\sqrt{\left[S^{2}\left(\frac{1}{n_{1}}+\frac{1}{n_{2}}\right)\right]}} \\
\mathrm{S}^{2}=\frac{\left(n_{1}-1\right) S_{1}^{2}+\left(n_{2}-1\right) S_{2}^{2}}{\left(n_{1}-1\right)+\left(n_{2}-1\right)}
\end{gathered}
$$

Pengujian hipotesis uji beda ratarata pendapatan usahatani tebu pada penelitian ini digunakan kaidah pengujian sebagai berikut : a. Jika $\mathrm{t}_{\text {bit }}>\mathrm{t}_{\text {tab, }}$ maka terima $\mathrm{H}_{\mathrm{a}} \mathrm{dan}$ tolak $\mathrm{H}_{0}$. Artinya terdapat perbedaan yang nyata antara pendapatan usahatani tebu petani kredit KKP-E dengan pendapatan usahatani tebu petani non KKP-E.

b. Jika $\mathrm{t}_{\text {bit }} \leq \mathrm{t}_{\text {tab }}$, maka terima $\mathrm{H}_{0}$ dan tolak $\mathrm{H}_{\mathrm{a}}$. Artinya tidak terdapat perbedaan yang nyata antara pendapatan usahatani tebu petaniKKP-E dengan pendapatan usahatani tebu petani non KKP-E.

\section{HASIL DAN PEMBAHASAN}

Analisis usahatani dilakukan untuk mengetahui besarnya pendapatan yang diperoleh dari usahatani tebu petani KKP-E dan usahatani tebu petani non KKP-E. Berikut ini merupakan analisis usahatani tebu yang diperoleh dari petani responden dalam penelitian.

\section{Biaya Usahatani Tebu}

\section{a. Biaya Tetap}

Biaya tetap merupakan biaya yang besar kecilnya tidak dipengaruhi oleh jumlah produksi yang dihasilkan. Adapun biaya tetap yang dikeluarkan oleh petani responden di Desa Bakalan disajikan pada tabel 1.

Tabel 1. Biaya Tetap Per Ha Usahatani Tebu Petani KKP-E dan Petani Non KKP-E dalam Satu Kali Musim Tanam 2015/2016 Kecamatan Bululawang

\begin{tabular}{|c|l|c|c|}
\hline No & \multicolumn{1}{|c|}{ Komponen Biaya Tetap } & $\begin{array}{c}\text { Petani KKP-E } \\
(\mathrm{Rp} / \mathrm{Ha})\end{array}$ & $\begin{array}{c}\text { Petani Non KKP-E } \\
(\mathrm{Rp} / \mathrm{Ha})\end{array}$ \\
\hline 1. & Biaya Pajak Lahan & 164.947 & 156.200 \\
2. & Biaya Bunga Kredit & 676.200 & - \\
\hline \multicolumn{2}{|c|}{ Total Biaya Tetap } & 841.147 & 156.200 \\
\hline
\end{tabular}

Sumber : Data Primer, 2016(Diolah)

\section{b. Biaya Variabel}

Biaya variabel merupakan biaya yang besar kecilnya dipengaruhi oleh besar kecilnya produksi yang dihasilkan.
Rincian biaya variabel yang dikeluarkan petani responden ditunjukkan dalam Tabel 2. 
N. Khoirunnisa dan R. P. D Julianto /Buana Sains Vol 17 No 2:181-188

Tabel 2. Biaya Variabel Per Ha Usahatani Tebu Petani KKP-E dan Petani Non KKP-E dalam Satu Musim Tanam 2015/2016Kecamatan Bululawang

\begin{tabular}{|c|c|c|c|}
\hline No & Komponen Biaya Variabel & $\begin{array}{c}\text { Petani KKP-E } \\
(\mathrm{Rp} / \mathrm{Ha})\end{array}$ & $\begin{array}{c}\text { Petani Non KKP-E } \\
(\mathrm{Rp} / \mathrm{Ha})\end{array}$ \\
\hline $\begin{array}{l}1 . \\
2 . \\
3 . \\
4 .\end{array}$ & $\begin{array}{l}\text { Biaya Bibit } \\
\text { Biaya Pupuk } \\
\text { Biaya Tenaga Kerja } \\
\text { Biaya Lain-Lain: } \\
\text { a. Pengolahan Pasca Panen } \\
\text { b. Hutang Ke PG } \\
\text { c. Fee KUD } \\
\text { d. Ongkos Angkut } \\
\text { e. Bunga Tebang Angkut }\end{array}$ & $\begin{array}{r}395.000 \\
3.367 .833 \\
8.039 .457 \\
\\
18.803 .162 \\
291.396 \\
290.153 \\
2.169 .212 \\
63.023\end{array}$ & $\begin{array}{r}387.500 \\
3.499 .500 \\
7.914 .037 \\
\\
17.984 .005 \\
278.583 \\
277.394 \\
2.027 .740 \\
58.913\end{array}$ \\
\hline & Total Biaya Variabel & 33.419 .236 & 32.427 .672 \\
\hline
\end{tabular}

Sumber : Data Primer, 2016(Diolah)

\section{c. Total Biaya Usahatani Tebu}

Rincian total biaya usahatani tebu yang dikeluarkan petani responden ditunjukkan dalam tabel 3. Data tersebut berkenaan tentang rata-rata total biaya per Ha usahatani tebu petani KKP-E dan petani non KKP-E dalam satu musim tanam 2015/2016 Kecamatan Bululawang

Tabel 3. Total Biaya Per Ha Usahatani Tebu Petani KKP-E dan Petani Non KKP-E Dalam Satu Musim Tanam 2015/2016 Kecamatan Bululawang

\begin{tabular}{|l|l|c|c|}
\hline \multirow{2}{*}{ No } & \multicolumn{1}{|c|}{ Komponen Biaya } & \multicolumn{2}{|c|}{ Biaya Total } \\
\cline { 3 - 4 } & & $\begin{array}{c}\text { Petani KKP-E } \\
\text { (Rp/Ha) }\end{array}$ & $\begin{array}{c}\text { Petani Non } \\
\text { KKP-E } \\
(\mathrm{Rp} / \mathrm{Ha})\end{array}$ \\
\hline 1 & Biaya Pajak Lahan & 164.947 & 156.200 \\
& Bunga Kredit & 676.200 & - \\
\hline Total Biaya Tetap & 841.147 & 156.200 \\
\hline 2 & Biaya Bibit & 395.000 & 387.500 \\
& Biaya Pupuk & 3.367 .833 & 3.499 .500 \\
& Biaya Tenaga Kerja & 8.039 .457 & 7.914 .037 \\
& Biaya Lain-Lain: & 18.803 .162 & 17.984 .005 \\
& a. Pengolahan Pasca Panen & 291.396 & 278.583 \\
& b.Hutang Ke PG & 290.153 & 277.394 \\
& c.Fee KUD & 2.169 .212 & 2.027 .740 \\
& d.Ongkos Angkut & 63.023 & 58.913 \\
\hline T. Bunga Tebang Angkut & 33.419 .236 & 32.427 .672 \\
\hline Total Biaya Variabel & 34.260 .383 & 32.583 .872 \\
\hline \multicolumn{2}{|c|}{ Total Biaya Usahatani Tebu } \\
\hline
\end{tabular}

Sumber : Data Primer, 2016(Diolah) 
N. Khoirunnisa dan R. P. D. Julianto /Buana Sains Vol 17 No 2 : 181-188

Hasil penelitian menunjukkan bahwa total biaya usahatani tebu yang dikeluarkan petani KKP-E lebih tinggi jika dibandingkan dengan total biaya usahatani tebu yang dikeluarkan oleh petani non KKP-E.

\section{Produktivitas Usahatani Tebu}

Produktivitas usahatani tebu merupakan total produksi dari usahatani tebu per satuan hektar. Produktivitas pada masing-masing petani tebu responden sangat beragam. Hal tersebut dapat dipengaruhi oleh tingkat kesuburan tanah dan banyaknya keprasan yang telah dilakukan pada lahan garapan usahatani tersebut. Karena semakin banyak keprasan yang dilakukan akan menurunkan tingkat kesuburan tanah. Rata-rata produktivitas usahatani tebu yang diterima petani responden ditunjukkan dalam tabel 4 .

Tabel 4. Produktivitas Per Ha Usahatani Tebu Petani KKP-E dan Petani Non KKP-E Dalam Satu Musim Tanam 2015/2016 Kecamatan Bululawang

\begin{tabular}{|c|l|c|}
\hline No. & \multicolumn{1}{|c|}{ Komponen Petani Tebu } & $\begin{array}{c}\text { Rata-Rata Produktivitas Usahatani } \\
\text { Tebu (ton/ha) }\end{array}$ \\
\hline 1. & Petani KKP-E & 83.5 \\
\hline 2. & Petani Non KKP-E & 78.0 \\
\hline
\end{tabular}

Sumber : Data Primer, 2016(Diolah)

\section{Penerimaan Usahatani Tebu}

Pada usahatani tebu, penerimaan merupakan jumlah fisik tebu yang dinilai dengan uang, sedangkan perhitungan penerimaannya dilakukan dengan menghitung nilai uang dari nilai gula dan nilai tetes.Penerimaan pada masing- masing petani responden sangat beragam. Hal ini dipengaruhi oleh jumlah produksi yang dihasilkan setiap satuan luas, rendemen yang diterima petani dan juga harga lelang gula. Rata-rata penerimaan yang diterima petani responden ditunjukkan dalam tabel 5 .

Tabel 5. Penerimaan Per Ha Usahatani Tebu Petani KKP-E dan Petani Non KKP-E Dalam Satu Musim Tanam 2015/2016 Kecamatan Bululawang

\begin{tabular}{|c|c|c|c|}
\hline No & Komponen Penerimaan & $\begin{array}{c}\text { Petani KKP-E } \\
(\mathrm{Rp} / \mathrm{Ha})\end{array}$ & $\begin{array}{c}\text { Petani Non KKP-E } \\
(\mathrm{Rp} / \mathrm{Ha})\end{array}$ \\
\hline 1. & Penerimaan dari unsur gula & 55.303 .417 & 52.894 .133 \\
2. & Penerimaan dari unsur tetes & 1.669 .267 & 1.560 .483 \\
\hline \multicolumn{2}{|c|}{ Total Penerimaan } & 56.972 .684 & 54.454 .616 \\
\hline
\end{tabular}

Sumber : Data Primer, 2016(Diolah) 


\section{Pendapatan Usahatani Tebu}

Pendapatan usaha tani merupakan selisih antara penerimaan usahatani tebu dengan total biaya usahatani yang dikeluarkan. Rata-rata pendapatan tiap hektar pada masingmasing petani dapat dilihat pada tabel 6 berikut ini.

Tabel 6. Pendapatan Per Ha Usahatani Tebu Petani KKP-E dan Petani Non KKP-E Dalam Satu Musim Tanam 2015/2016 Kecamatan Bululawang

\begin{tabular}{|l|c|c|c|}
\hline $\begin{array}{c}\text { Komponen Petani } \\
\text { Tebu }\end{array}$ & $\begin{array}{c}\text { Total Biaya } \\
(\mathrm{Rp} / \mathrm{Ha})\end{array}$ & $\begin{array}{c}\text { Penerimaan } \\
(\mathrm{Rp} / \mathrm{Ha})\end{array}$ & $\begin{array}{c}\text { Pendapatan } \\
(\mathrm{Rp} / \mathrm{Ha})\end{array}$ \\
\hline & & & \\
Petani KKP-E & 34.260 .383 & 56.972 .684 & 22.712 .301 \\
Petani Non KKP-E & 32.583 .872 & 54.454 .616 & 21.870 .744 \\
\hline
\end{tabular}

Sumber : Data Primer, 2016(Diolah)

5. Uji Beda Rata-Rata Pendapatan Usahatani Tebu

Setelah pendapatan dari usahatani tebu petani KKP-E dan petani non KKP-E diketahui, selanjutnya dilakukan analisis uji beda rata-rata dengan bantuan software SPSS. Berdasarkan hasil uji beda ratarata tersebut menunjukkan bahwa nilai $\mathrm{f}_{\text {hitung }}=3.233$ pada nilai probabilitas 0.080 , karena probabilitas $>0.05$ maka dapat disimpulkan bahwa H0 tidak dapat ditolak atau memiliki ragam yang sama. Dengan demikian analisis uji beda t-test harus menggunakan asumsi equal variance assumed(kedua populasi tersebut memiliki varian yang sama). Dari hasil uji t-test, terlihat bahwa nilai t pada equal variance assumed yaitu 0.379 dengan probabilitas signifikansi 0.354 yang nilai tersebut tidak signifikan terhadap tingkat kepercayaan yang sebelumnya telah ditentukan yaitu 5\%. Dapat disimpulkan bahwa antara rata-rata pendapatan usahatani petani KKP-E dan rata-rata pendapatan petani non KKP-E tidak memiliki perbedaan yang signifikan. Hal tersebut dikarenakan perbedaan komponen penyusun biaya usahatani antara petani KKP-E dan petani non KKP-E hanya terdapat pada pengambilan kredit atau tidak, sehingga perbedaan yang mendasar hanya pada ada tidaknya bunga KKP-E.

\section{Kesimpulan}

Berdasarkan analisis pendapatan usahatani tebu, tidak terdapat perbedaan antara pendapatan usahatani tebu petani KKP-E dengan petani non KKP-E. Hasil rata-rata pendapatan usahatani pada petani KKP-E yakni sebesar Rp. 22.712.301.dan pada petani non KKP-E sebesar Rp. 21.870.744.-. Selisih pendapatan pada keduanya sebesar Rp. 841.557.-. Karena hal mendasar yang membedakan usahatani antara petani KKP-E dan non KKP-E hanya terdapat pada adanya bunga kredit yang harus dibayar oleh petani KKPE.

\section{Daftar Pustaka}

Ashari. 2009. Optimalisasi Kebijakan Kredit Program Sektor Pertanian diIndonesia. Analisis Kebijakan Pertanian Volume 7 Nomor 1: 21-42.

Badan Litbang. Departemen Pertanian. 2008. Konsumsi Gula 
di Indonesia Tabun 2003-2007. Surabaya. Jawa Timur.

Dewan Gula indonesia. 2011. Bunga Rampai Peraturan Pergulaan Indonesia. Sekretariat Dewan Gula Indonesia. Jakarta.

Ellis, F. 1992. Agricultural Policies In Developing Countries. Cambridge University Press. Cambridge

Fajrina, N. A. 2012. Analisis Pengaruh Kredit Ketahanan Pangan Dan Energi Terbadap Pendapatan Petani Padi Di Kabupaten Karanganyar. Jurnal Agribisnis Fakultas Pertanian Universitas Sebelas Maret Surakarta.

Suara Merdeka, 2013. Gerakan Sapta Usabatani Perlu Di tingkatkan.http://suaramerde ka.com/v1/index.php.

Diakses pada tanggal 28 September 2016.

Susilowati, S.H dan Netti Tinaprilla. 2012. Analisis Efisiensi Usaha Tani Tebu di Jawa Timur. Jurnal Littri 18(4), Halaman 162-172.

Wahyudi, A.,dan Suci W. 2000. Analisis Sistem Perkereditan Usahatani Tebu. Jurnal Sosial Ekonomi Volume 1 Nomor 1.

Wibowo, Edy. 2013. Pola Kemitraan Antara Petani Tebu Rakyat Kredit (TRK) dan Mandiri (TRM) Dengan Pabrik Gula Modjopanggoong Tulungagung. Jurnal Manajemen Agribisnis, Volume 13 Nomor 1. 